\title{
Active Learning Applied to Introductory Programming
}

\author{
Jeffrey L. Duffany, Ph.D. ${ }^{1}$ \\ ${ }^{1}$ Universidad del Turabo, Puerto Rico, U.S.A., jeduffany@suagm.edu
}

\begin{abstract}
Over the past few decades there has been a movement to try to incorporate active learning techniques into traditional university classes. The main idea is that traditional classroom learning is very passive with the professor lecturing and the students listening. Active learning tries to engage students with a variety of techniques which are mainly variations of traditional teaching techniques. This paper provides an overview of how active learning techniques might be applied to introductory programming classes and gives several specific examples of how this might be done.
\end{abstract}

Keywords - active learning, introductory programming

Digital Object Identifier (DOI): http://dx.doi.org/10.18687/LACCEI2015.1.1.246

ISBN: 13 978-0-9822896-8-6

ISSN: 2414-6668 


\title{
Active Learning Applied to Introductory Programming
}

\author{
Jeffrey L. Duffany, Ph.D. \\ Universidad del Turabo, Puerto Rico, U.S.A., jeduffany@suagm.edu
}

\begin{abstract}
Over the past few decades there has been a movement to try to incorporate active learning techniques into traditional university classes. The main idea is that traditional classroom learning is very passive with the professor lecturing and the students listening. Active learning tries to engage students with a variety of techniques which are mainly variations of traditional teaching techniques. This paper provides an overview of how active learning techniques might be applied to introductory programming classes and gives several specific examples of how this might be done.
\end{abstract}

Keywords-- active learning, introductory programming

\section{INTRODUCTION}

Active learning[1][6] is a model of instruction that tries to engage the student with a variety of techniques which are mainly variations of traditional teaching techniques. Doing homework and participating in study groups are examples of active learning that usually take place outside the classroom. The idea is to reduce the amount of passive learning in the classroom and replace it with active learning techniques by modifying the way things are done and incorporating things normally done outside the classroom into the classroom environment. Research studies have shown[5][7][15] that introducing active learning activities before, rather than after lectures or readings, results in deeper learning, understanding, and transfer. The degree of guidance in active learning will vary according to subject material, the students and the instructor.

\section{TRADITIONAL TEACHING METHODOLOGY}

Traditional teaching is by lecture [4]which is a variation on the Socratic method. However, modern university courses need to deliver a lot of material and the Socratic method is just too inefficient. As a result, the lecture method (which can be seen to be a variation on the Socratic method) is commonly used. One person who is designated by some authority as some kind of an expert gives an oral presentation in the form of a lecture to teach an audience about a particular subject. Usually the lecturer stands at the front of the room and has an essentially one-way conversation covering the important aspects of the subject matter. Though lectures are much criticized as a teaching method, no one has yet found any practical alternative teaching method. Critics point out that lecturing is mainly a one-way method of communication that does not involve significant audience participation.
With traditional teaching students sit through the lecture, take notes and watch the professor work some examples. The students then go home and try to remember what they learned. There are a number of problems with this traditional approach. Outside of the classroom there can be many demotivators and few if any motivators (except for perhaps the grade) while there are many distractors and interruptors. There is also the tendency to procrastinate.

\section{ACTIVE LEARNING}

Active learning is considered to be any form of learning where the student is doing something besides just listening[8][9][10][11][12][13][14]. In reality, many forms of active learning are really not much different than traditional learning and are simply modified versions of the traditional learning techniques. Take for example homework which has been one of the cornerstones of modern learning. Doing homework can be regarded as active learning assuming that the student is not just wasting time staring at the textbook not knowing what to do. If the student makes a valid attempt to do the homework and cannot then they are more likely to be motivated to pay attention when the instructor goes over the homework problems. Problem based learning[7] is for the most part yet another a variation on doing homework.

The quintessential example of active learning is called the inverted classroom where students watch video lectures for homework and do the homework assignments in class. However this approach is not always practical. It requires the professor to take time and effort to create the alternative learning experience. Outside the classroom the students want (need?) to be entertained so it does make some sense to have an inverted classroom. It allows the student to adapt the learning to their schedule or mood while the traditional system forces the student to be present at a certain place at a certain time for a specified period of time. In a traditional classroom students cannot simply take breaks whenever they want without missing part of the instruction.

The inverted classroom addresses many of the issues that arise in the context of the traditional classroom. Students watch the video instruction at home then do the written assignment while they are in class. The obvious advantage is that the students can watch the video whenever they like and they can start and stop the video whenever they like. They can play the video over and over several times if the like. The other advantage is that while outside

$1^{\text {th }}$ LACCEI Annual International Conference: “Engineering Education Facing the Grand Challenges, What Are We Doing?” 
the classroom there is little motivation while that is significantly different when inside the classroom. First of all the presence of a roving instructor means that someone is observing therefore impacting on the students behaviour. Second is the peer pressure. No one wants to look bad by getting behind in a class activity. So the inverted classroom does make sense but it is not practical to assume that all professors will be able to adopt the new teaching paradigm or that it always makes sense to do so. There are always barriers to the adoption of any new method.

Another active learning technique is called learning by teaching. One way this can occur is simply a byproduct of incorporating the homework assignments into the classroom environment. What tends to happen is that spontaneous study groups tend to form where the more knowledgeable students end up teaching the students that do not pick up the subject material quite as quickly. It is clear that this is largely an adaptation of the traditional study group concept except it is more spontaneous and has more to do with who happens to be sitting where in that particular classroom at that particular time. The problem with traditional study groups is that they have a tendency to become more of a social activity and lose focus on the original objective. However when brought into the classroom under the supervision of the instructor cooperative learning can become a powerful active learning technique.

\section{INDUCTIVE VS. DEDUCTIVE LEARNING}

Deductive learning goes from the general to the specific while inductive learning goes from the specific to general. Traditional teaching and the lecture method are primarily deductive. With deductive learning the instructor presents a general principle and illustrates it with examples. However this is not how human beings have learned their entire lives as people learn primarily by experience. An adult can tell a child a hundred times not to touch a stove however if a child touches a hot stove once he or she quickly generalizes that experience. For that reason people tend to learn better inductively. What this means in the traditional classroom environment is that instructors are spending a lot of time explaining materials to an audience that does not really comprehend the relevance of what is being explained. The idea of inductive learning would be to reverse the order of presentation. In other words the instructor could give some examples and show how to solve a specific problem. Once the students have seen several examples they have already begun to generalize the solution technique in their own minds and are more predisposed to listen to a more general explanation. The concept of problem based learning attempts to extend this idea even further by just giving the examples first and challenging the student try to solve it with only what they already know or with only minimal guidance. Only when the student indicates that they are completely lost or stuck do you proceed to provide them with the help that they need. The benefit of this approach is that you are giving them the tools that they need when they need them and not before.

\section{ACTIVE LEARNING In INTRODUCTORY PROGRAMMING}

Many students do not seem to be highly motivated to learn the material of introductory programming and as a result many perform poorly in the course. Some students just want to pass the course and that is not too surprising. It would be natural for a student to feel that it is unfair to learn programming if they have are majoring in mechanical or industrial engineering and have no intention of being a computer programmer. So there is little motivation except for perhaps the grade an the fact that it is a required course. Many students no doubt view it as a throw-away course with little more value than doing some mental calisthenics.

The average student in an introductory programming class may have little motivation for learning the subject material except for the grade but is the grade a sufficient motivator? I think not. There is an inherent assumption that someone made an informed decision at some point that this was good idea for the students to learn this material. However students might be more motivated to learn if there was some tangible benefit that would help them in some way in the future. Some examples how knowledge of computer programming might benefit the students are:

- $\quad$ solving homework problems

- $\quad$ solving problems on take home tests

- analyzing lab data

It probably would not hurt to have a brief discussion at the beginning of the course to indicate what are some of the possible benefits of learning how to program as a way of providing motivation and as a way to encourage more active learning behaviour.

The goal of any course is usually to enlighten the student about the subject material, to inform them about something they perhaps didn't know and possibly even give them a skill that can be reused again and again[2]. Each class you take is part of a larger process of becoming[2]. In any event the overall goals of an engineering education need to be kept in mind. Some of the main goals of an introductory programming course[3] might be:

- teach basic programming skills

- reinforce mathematical concepts

- learn logical thinking

- develop problem solving abilities

- develop critical thinking skills

For any given class has there is a variety of material to be learned. Some of it will be retained but most will be 


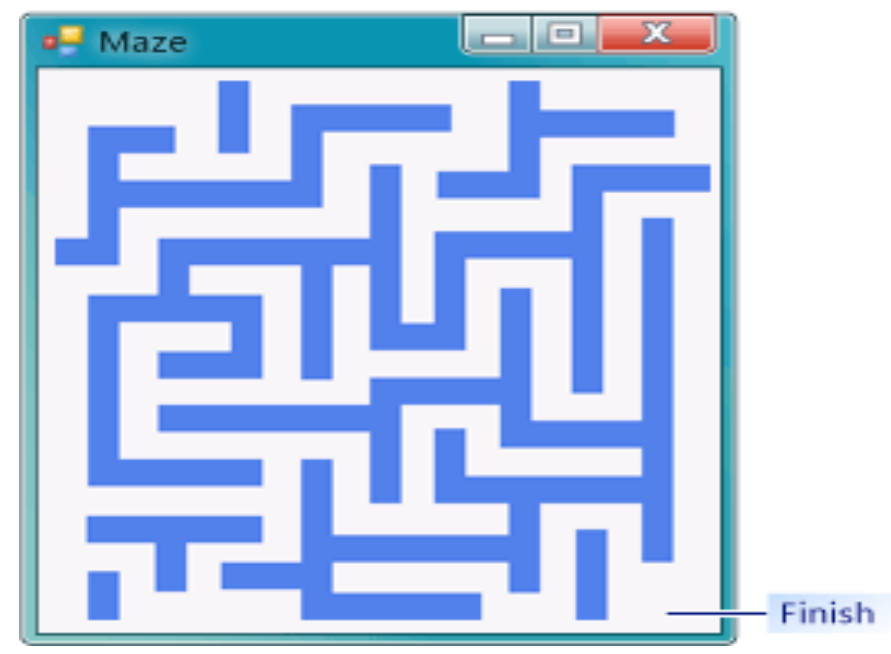

Fig. 1 Visual Basic Maze Tutorial

forgotten. Perhaps some core skills might be learned. At the very least it will make it easier to or the student to learn it again or look it up when needed for a subsequent university course or after the student enters the domain of the practicing engineer. Critical thinking should be a byproduct of the overall engineering education and each course should contribute to its development.

\section{SPECIFIC ACTIVE LEARNING EXAMPLES}

The following is a list of some possible methods for incorporating active learning into an Introductory Programming Course. These are intended to be representative of the kinds of things that can be done using active learning techniques.

A. Write, compile and run first computer program

B. Tutorial - Picture Viewer or Maze Program

C. Learn how to cook spaghetti.

D. Flowchart Creation - Telephone Call

E. Use programming environment

F. Use the debugging tool

\section{A. Write, compile and run their first computer program}

On the first day of class, after the instructor goes over the syllabus and makes a few introductory statements about the visual studio programming environment the students can write, compile and run their first computer program. For example the students could run a simple three line program to print something on the screen as follows:

Sub Main()

MsgBox("hello kitty")

end Sub
The first class sets the tone for the entire course. It should build confidence that the student is able to use the programming environment and are able to write, compile run and if necessary debug a visual basic program. Students learn about subroutines $\operatorname{Sub}()$ and the MsgBox() command which prints out whatever is in parentheses on the screen.

\section{B. Maze Program Tutorial}

One advantage of using visual studio is that there are some introductory tutorials available on the web. There are a total of 4 tutorials: Picture Viewer, Maze Game, Math Quiz and Memory Game. Being game oriented these have an inherent appeal to the students. Each of the tutorials includes a series of videos and step by step instructions. The instructor can show the videos first and then the students can follow the step by step tutorial while the instructor is assisting students who get stuck or make mistakes. This technique is also known as immersion. Students will be using programming concepts before they are receive any instruction thus familiarizing them with the terminology and the code structure so it will be easier to explain later on. The students will be using methods, variables and "if" statements before they even know what they are.

Figure 1 shows a screen capture of the Maze Tutorial program. Students get to use their own creativity to create whatever maze they like. They control the color and size of the walls as well as the configuration of the maze. By doing this they learn about containers, controls, mouse events, labels, and various kinds of objects (and their properties) without the instructor having to explain what all those things are. Students are encouraged to help other students (especially if they are among the first to finish). 


\section{How to cook spaghetti}

1. boil water

2. put spaghetti in boiling water

3. heat tomato sauce

4. check to see if done

a. remove spaghetti sample

b. cut along cross-section

c. evaluate doneness

d. al dente, etc.

5. if done then serve immediately

6. if not done go to step 4

\section{How To Cook Spaghetti}

In this type of active learning the instructor pretends to know nothing about the subject matter. The students are called on to collectively work together to come up with a plausible recipe for cooking spaghetti, suitable as a step by step instruction. This is important because a computer must be told exactly what to do, no ambiguity is allowed. This amounts to a type of role reversal where the students are placed in the active role of responsibility to collaboratively come up with the solution to a challenge. Cooking spaghetti is something that every student can relate to in one way or another and each student has their own version of the recipe. Once the procedure is agreed upon, a flowchart can be created (Figure 2). It is at this point that the flowchart symbols can be introduced. The usual result is that no student in the class will know how to determine when the spaghetti is done. This is also an opportunity to teach critical thinking. Students will generally know how to determine if a roast is cooked but few people will apply that same level of formalism to the process of cooking spaghetti by cutting open a strand of spaghetti and examining the cross sectional area (as shown in Figure 2) then repeating this process until the desired doneness is achieved (al dente, etc.). This also gives the students an early introduction to repetition loops. As a follow on exercise, students can be allowed to search for images of flowcharts on the internet which can then be displayed on the screen and critiqued.

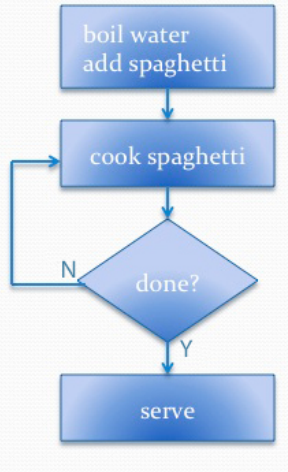

stages of cooking spaghetti

(a) raw

(b) half-cooked

(c) al dente

(d) fully cooked

Figure 2. How to Cook Spaghetti

\section{Individual Flowchart Creation}

The preceding exercise was a group effort involving all of the class members. To further reinforce the concept it is at times good practice to provide an exercise that reflects more of the individual creativity. To follow up on the flowchart exercise you can have the students take some daily activity such as making a phone call and try to make a flowchart to represent the various possibilities of what could happen during that activity (Figure 3).

Flowchart for a telephone call

a. dialing the number

b. what if the line is busy?

c. the person you are calling answers

d. someone else answers

e. no one answers

f. answering machine answers

g. other possibilities

h. use your imagination

i. creativity and experience

Figure 3. Telephone Call Flowchart Exercise 


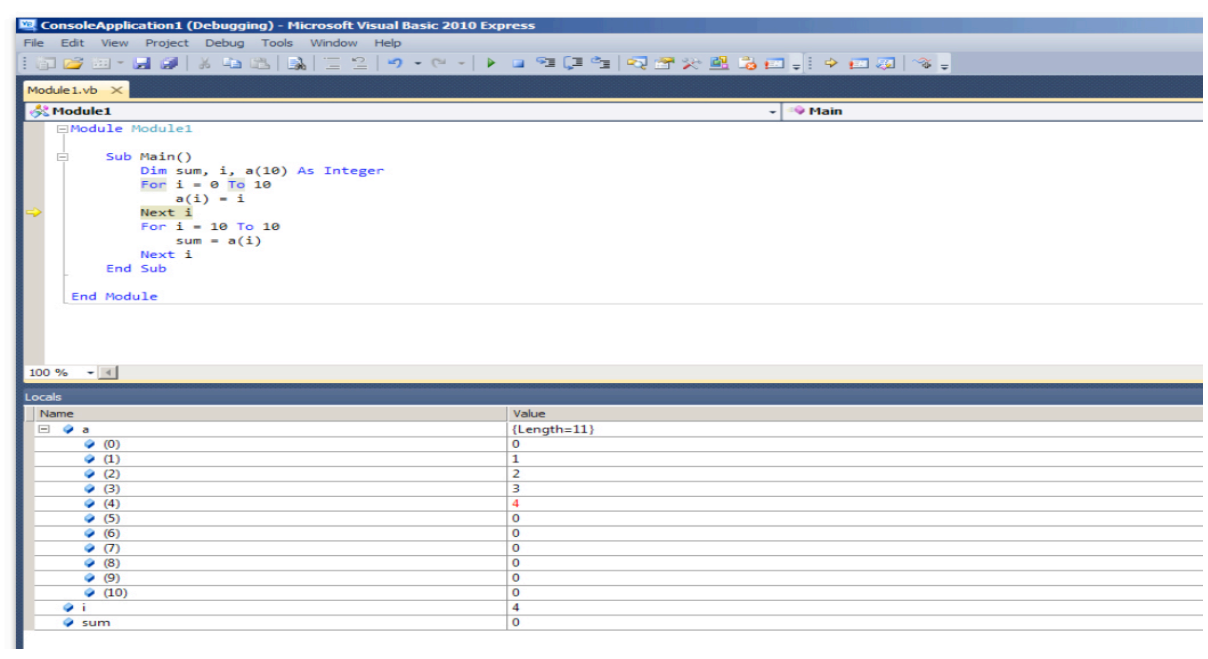

Figure 5. Visual Studio Debugging Tool

\section{E. The Visual Studio Programming Environment}

This exercise is a method to teach the operation of visual basic commands by having the students analyze the command output. Students are given a piece of paper with the executable program shown in Figure 4. By looking at the program it is not easy to figure out what is going on. If the student now opens visual studio and types in the program and then runs the program they will see the result of each command $(\operatorname{MsgBox}()$ is visual studio command to print out something). The dimension statement (Dim) creates variables $\mathrm{x}$ and $\mathrm{y}$ to hold text. Next those variables are assigned text values. Here is the visual basic code and the output:

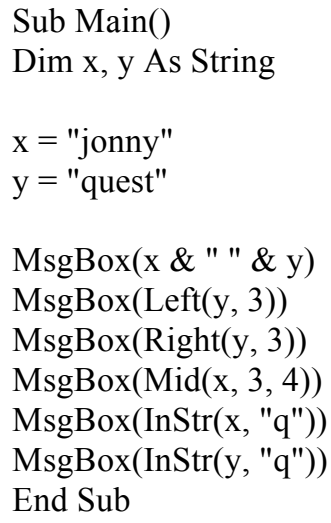

Figure 4. Visual Basic Code
Students are challenged to figure out from the output what the commands are doing. Since it is an interactive environment, they are able to edit the commands and see how the result changes. This encourages exploration and curiosity and is typical of the active learning technique. After a few minutes the students will figure out that Left, Right and Mid extract various substrings from the specified string. Left $(y, 3)$ takes the left 3 characters from string y and prints the substring "que" on the screen. $\operatorname{Right}(\mathrm{y}, 3)$ prints "est" on the screen while $\operatorname{Mid}(\mathrm{x}, 3,4)$ prints " $\mathrm{nn}$ " on the screen. The command InStr (In String) is less obvious. $\operatorname{InStr}(\mathrm{x}, \mathrm{q})$ looks for character "q" in string $\mathrm{x}$ and if present returns an integer representing the location of the character in the string. $\operatorname{InStr}(\mathrm{y}, \mathrm{q} ")=1$ as seen in Figure 4. If the character is not present InStr returns "0": $\operatorname{InStr}(\mathrm{x}, " \mathrm{q} ")=0$.

\section{F. The Visual Studio Debugging Environment}

Another highly interactive technique is to use the builtin debugging tools to sharpen and reinforce programming language understanding and skills (Figure 5). Visual studio debugging tools allow you to step through and execute one line of code at a time and is usually used by professional programmers. For example in Figure 5 the student can step through the FOR/NEXT loop and watch dynamically how the local variables change each time he or she executes the next line of code. At this point in time the array values a $(0)$ through a(4) have already been set and the yellow arrow indicates that "NEXT $i$ " will execute incrementing the value of i (currently with a value of 4) to 5 . The second FOR/NEXT loop has intentionally introduced errors and the students improve their ability to read computer code by finding the errors using the debugging tools.

13 $^{\text {th }}$ LACCEI Annual International Conference: "Engineering Education Facing the Grand Challenges, What Are We Doing?" 


\section{DISCUSSION}

One simple method for the implementation of active learning techniques is to have the students do all or a part of their homework as a part of the regular class time period. This might seem impossible without significantly sacrificing the amount of material covered but sometimes less is actually more. Doing this has the side benefit of creating spontaneous small ad-hoc study groups that form temporarily so that the students can help their classmates. This works for a wide variety of courses but might not be practical for some other courses where perhaps covering a lot of subject material might be more important than the kind of learning that can come from peer interaction. On the other hand, this style of teaching may actually reduce the amount of up-front instruction required which in many cases represents time inefficiently utilized. In the spirit of inductive vs. deductive learning, having the students complete their assignment in class means that the instructor can spend more time guiding the students and helping them overcome obstacles and gaps in their knowledge on a more individual basis.

\section{REFERENCES}

[1] Bonwell, C.; Eison, J. (1991). Active Learning: Creating Excitement in the Classroom AEHE-ERIC Higher Education Report No. 1. Washington, D.C.: Jossey-Bass. ISBN 1-878380-08-7.

[2] Bloom, B.(1956). Taxonomy of Educational Objectives: The Classification of Educational Goals. New York: McKay.

[3] Duffany, J.L. "Choice of Language for an Introductory Programming Course", LACCEI 2014 Conference, Guayaquil, Ecuador.

[4] McKeachie, W.J., Svinicki,M. (2006). Teaching Tips: Strategies, Research, and Theory for College and University Teachers. Belmont, CA. Wadsworth.

[5] Hake, R. R. (1998). Interactive-engagement versus traditional methods: A six-thousand-student survey of mechanics test data for introductory physics courses. American journal of Physics, 66, 64.

[6] R.M. Felder and R. Brent, "Active Learning: An Introduction." ASQ Higher Education Brief, 2(4), August 2009.

[7] L. Bullard, R.M. Felder, and D. Raubenheimer, "Effects of Active Learning on Student Performance and Retention." 2008 ASEE Annual Conference Proceedings, ASEE, June 2008.

[8] R.M. Felder and R. Brent, "Learning by Doing." Chem. Engr. Education, 37(4), 282--283 (Fall 2003).

[9] R.M. Felder and R. Brent, "FAQs-2." Chem. Engr. Education, 33(4), 276-277 (Fall 1999).

[10]R.M. Felder, "Any Questions?" Chem. Engr. Education, 28(3), 174175 (Summer 1994).

[11]R.M. Felder, "How About a Quick One?" Chem. Engr. Education, 26(1), 18-19 (Winter 1992).

[12]R.M. Felder, "It Goes Without Saying." Chem. Engr. Education, 25(3), 132-133 (Summer 1991)

[13]L.G. Bullard and R.M. Felder, "A Student-Centered Approach to Teaching Material and Energy Balances. Part 2. Course Delivery and Assessment." Chem. Engr. Education, 41(3), 167-176 (2007).

[14]R.M. Felder, "Stoichiometry without Tears." Chem. Engr. Education, 24(4), 188 (1990).

[15]M. Prince, "Does Active Learning Work? A Review of the Research." J. Engr. Education, 93(3), 223-231 (2004).

\section{SUMMARY AND CONCLUSIONS}

It would appear that many engineering courses taught in the traditional lecture format would be candidates for the adaptation of at least some active learning techniques. The techniques should preferably be spread throughout the course but introduced very early to gain student acceptance. Active learning should be used judiciously lest it upset the applecart of preconditioning since students have been accustomed and their entire lives to taking courses which probably did not incorporate active learning. It might be helpful to explain up front that you are using active learning techniques and provide a brief explanation of what those techniques are and how they work. The potential benefit of active learning is that it could improve retention for skills that are needed in future courses. Students are also likely to get more out of their courses more and may be less likely to change their major to something other than engineering. Also it is possible that they may pick up critical thinking skills that help them to become better students and subsequently better practitioners of their profession. 